\title{
Characterization of insulin-producing cells derived from PDX-1-transfected neural stem cells
}

\author{
HAILAN WANG ${ }^{1}$, ZESHENG JIANG $^{2}$, AIHUI LI $^{3}$ and YI GAO ${ }^{2}$ \\ ${ }^{1}$ Department of Endocrinology, Shenzhen Longgang Central Hospital, Shenzhen 518000; \\ ${ }^{2}$ Department of General Surgery, Zhujiang Hospital of South Medical University, Guangzhou 510120; \\ ${ }^{3}$ Department of General Surgery, Dongguan Donghua Hospital, Dongguan 523000, P.R. China
}

Received April 10, 2012; Accepted August 20, 2012

DOI: $10.3892 / \mathrm{mmr} .2012 .1089$

\begin{abstract}
Islet cell transplantation is a promising treatment strategy for type-1 diabetes. However, functional islet cells are hard to obtain for transplantation and are in short supply. Directing the differentiation of stem cells into insulin-producing cells, which serve as islet cells, would overcome this shortage. Bone marrow contains hematopoietic stem cells and mesenchymal stem cells. The present study used bone marrow cells isolated from rats and neural stem cells (NSCs) that were derived from bone marrow cells in culture. Strong nestin staining was detected in NSCs, but not in bone marrow stromal cells (BMSCs). In vitro transfection of the pancreatic duodenal homeobox-1 (PDX-1) gene into NSCs generated insulin-producing cells. Reverse transcription polymerase chain reaction (RT-PCR) and enzyme-linked immunosorbent assay (ELISA) analysis confirmed that PDX-1-transfected NSCs expressed insulin mRNA and released insulin protein. However, insulin release from PDX-1-transfected NSCs did not respond to the challenge of glucose and glucagon-like peptide-1. These results support the use of bone marrowderived NSCs as a renewable source of insulin-producing cells for autologous transplantation to treat type-1 diabetes.
\end{abstract}

\section{Introduction}

According to the website of the World Health Organization (http://www.who.int/diabetes/en/), 346 million individuals worldwide have diabetes. The chronic cardiovascular and metabolic complications of diabetes carry significant risks of morbidity and mortality, requiring that the disease is carefully managed. Type-1 diabetes, an autoimmune disorder, is characterized by the loss of insulin-producing $\beta$ cells. Pancreatic islet transplantation is one of the most successful therapeutic

Correspondence to: Dr Yi Gao, Department of General Surgery, Zhujiang Hospital of South Medical University, 253 Middle Industry Road, Haizhu, Guangzhou 510120, P.R. China

E-mail: gaoyi6146@163.com

Key words: bone marrow, nestin, neuron stem cell, pancreatic duodenal homeobox-1, insulin-producing cell, glucose strategies for diabetes (1-4). However, there are several obstacles for islet transplantation that must be overcome, including the adverse effects resulting from treatment with immunosuppressive drugs, preservation of islet function and the shortage of islet donors (5). Therefore, generating functional $\beta$ cells would be a promising strategy in providing adequate numbers of $\beta$ cells for transplantation.

Stem cells, including embryonic and adult stem cells, possess the potential for self-renewal, proliferation and differentiation into various types of cells. Stem cells may be isolated from embryo, pancreas, liver and bone marrow tissue and used as $\beta$ cells for transplantation (6,7). Hepatic stem cells have the highest potential for differentiation into insulin-producing cells, as the pancreas and liver have common precursor cells during embryogenesis. A study by Yang et al demonstrated the production of insulin-secreting $\beta$ cells from hepatic oval stem cells, this may be a therapeutic strategy for autologous stem cell transplantation (8). However, this application is limited since stem cells are difficult to obtain.

Bone marrow stromal cells (BMSCs), which have high plasticity and are therefore easily manipulated in vitro, are abundant in bone marrow and are readily obtained $(9,10)$. BMSCs may be isolated from other cells and cultured in vitro. Previous studies have shown that BMSCs differentiate into chrondrocytes, osteocytes, adipocytes and fibroblasts $(11,12)$. Tang et al demonstrated that mouse BMSCs differentiate into insulin-producing cells (13). Moreover, genetically manipulated human BMSCs show stable transgene expression from over 17 passages in vitro and over 3 months in vivo (14). Therefore, BMSCs are a promising source of insulin-producing cells for autologous transplantation.

Nestin, a type VI intermediate filament protein, promotes the phosphorylation-dependent disassembly of vimentin intermediate filaments during mitosis (15) and is also used as a marker of neural precursor cells (16) and pancreatic stem cells (17). Studies suggest that cerebral microglia expressing nestin and NG2, a chondroitin sulfate proteoglycan, have high plasticity similar to neonatal brain neurons $(18,19)$. Moreover, Milanesi et al demonstrated that nestin-positive cells differentiate into pancreatic endocrine cells in vitro (20). Taguchi and Otsuki reported that PDX-1 staining was detected in small evaginations of the main pancreatic duct and in the nuclei of islet cells; nestin-positive staining was also detected in small 
evaginations of the main duct, islets and spindle-shaped cells in the connective tissue around the main duct (17). These authors proposed that the nestin and PDX-1 double-positive cells were pancreatic stem cells. PDX-1 plays a significant role during the formation of the pancreas by regulating insulin secretion. PDX-1 has been reported to be capable of reprogramming extrapancreatic tissue towards a $\beta$-cell phenotype (21). When implanted under the renal capsule of NOD-SCID mice, PDX-1transfected liver cells transdifferentiated into insulin-producing cells, which reduced hyperglycemia (22). Therefore, the PDX-1 gene is significant in regulating the production of insulin.

The objective of the current study was to examine bone marrow-derived neural stem cells (NSCs) as a renewable source of insulin-producing cells for autologous transplantation.

\section{Materials and methods}

Isolation and culture of BMSCs and neuron-like cells. Sprague-Dawley rats 3-4 weeks old (60-70 g) were obtained from the Laboratory Animal Center of South Medical University (Guangzhou, China). The rats were sacrificed by cervical dislocation and placed in $75 \%$ alcohol for $1 \mathrm{~min}$. The two femurs were removed and bone marrow cells were flushed from the marrow with a 1-ml syringe filled with L-DMEM containing $100 \mathrm{U} / \mathrm{ml}$ heparin. The cell suspension was centrifuged at $400 \mathrm{rpm}$ for $8 \mathrm{~min}$. The supernatant was discarded and the cells were resuspended with L-DMEM; cells were then layered over lymphocyte isolation reagent (Institute of Hematology and Blood Diseases Hospital, Chinese Academy of Medical Sciences) and centrifuged at 2,500 rpm for $20 \mathrm{~min}$ at $25^{\circ} \mathrm{C}$. Mononuclear cells were removed from the gradient interface and washed twice with PBS. For BMSCs, the pellet was resuspended with L-DMEM (containing 10\% FBS) and plated in tissue-culture flasks at a density of $1 \times 10^{6}$ cells $/ \mathrm{ml}$. For neuronal stem cells, the pellet was resuspended with neuronal stem cell culture medium (patent no. 02134314.4, Neurosurgery Lab, South Medical University) and plated in tissue-culture flasks at a density of $1 \times 10^{7}$ cells $/ \mathrm{ml}$. Half of the culture medium was removed following the first $48 \mathrm{~h}$. The cells were then passaged until cell growth reached $70-80 \%$ confluence. The study was approved by the ethics committee of Shenzhen Longgang Central Hospital, Shenzhen, China.

Immunocytochemical staining. The fourth passage of MSCs and first passage of NSCs were fixed with $4 \%$ paraformaldehyde for $15 \mathrm{~min}$, washed 3 times with distilled water and incubated with $0.03 \%$ Triton X-100 for $10 \mathrm{~min}$. Cells were washed 3 times with PBS and subsequently incubated with $30 \% \mathrm{H}_{2} \mathrm{O}_{2}$ in methanol (1:50) for $30 \mathrm{~min}$. Cells were then washed with distilled water 3 times and non-specific binding was blocked with $5 \%$ BSA for $20 \mathrm{~min}$ at room temperature. Cells were then incubated with primary antibodies against nestin (Beijing Biosysnthesis Biotechnoloy Co., Ltd., Beijing, China) with 1:100 dilutions for $1 \mathrm{~h}$ at room temperature, washed 3 times with PBS and incubated with SABC reagent (Beijing Biosysnthesis Biotechnology) for $20 \mathrm{~min}$ at room temperature. The cells were counter-stained with propidium iodide (PI) to detect nuclei, observed using an Olympus phase contrast microscope (CK-2; Olympus Optical Co. Ltd., Tokyo, Japan) and images were captured with an Olympus PM-CBAD exposure control unit (Olympus, Centre Valley, PA, USA). Fluorescence of cells was observed with an inverted fluorescence microscope (Leica, Mannheim, German).

Reverse-transcription polymerase chain reaction (RT-PCR). Total RNA of BMSCs and NSCs was extracted with TRIzol (Gibco, Carlsbad, CA, USA) and reverse transcribed to cDNA with an RT-kit (Tiangen Biotech, Beijing, China). RT-PCR was performed as follows: the amplification reaction was carried out with preliminary denaturing at $95^{\circ} \mathrm{C}$ for $3 \mathrm{~min}$ followed by 35 cycles of the following conditions: $94^{\circ} \mathrm{C}$ for $55 \mathrm{sec}, 55^{\circ} \mathrm{C}$ for $45 \mathrm{sec}, 72^{\circ} \mathrm{C}$ for $1 \mathrm{~min}$ and $72^{\circ} \mathrm{C}$ for $8 \mathrm{~min}$. The following primers for nestin were used: forward, 5'-GCGGGGCGG TGCTGATAC-3'; reverse, 5'-AGGCAAGGGGGAAGA GAAGGATGT-3' and the expected size of the PCR product was 326 bp. PDX-1 primers were forward, 5'-CGGCCACAC AGCTCTACAAGG-3'; reverse, 5'-GAGGTTACGGCA CAATCCTGA-3' and the expected size of the PCR product was $667 \mathrm{bp}$. The insulin primers were forward, 5'-CGGGAG GATGGGCTTTTCTG-3'; reverse, 5'-AGCTGCTTTTGG TTGAGCACAG-3' and the expected size was $191 \mathrm{bp}$.

Transfection. The fourth passage of MSCs and 7-day cultures of nestin-positive cells were dissociated from culture dishes with $0.25 \%$ trypsin-EDTA. Cells were washed and resuspended at a density of 3 to $4 \times 10^{6}$ cells $/ \mathrm{ml}$ in Nucleofector ${ }^{\circledR}$ solution. Cell suspension $(100 \mu \mathrm{l})$ and $5 \mu \mathrm{g}$ pBluescript-EGFP-C2-PDX-1 plasmid were mixed and transferred into electroporation cuvettes. The A33 Nucleofector ${ }^{\circledR}$ Program was selected to transfect cells. Following transfection, $4 \mathrm{ml}$ L-DMEM was added for culture and after $24 \mathrm{~h}$, cellular morphology was observed by fluorescence microscopy.

Fluorescent-activated cell sorting (FACS). Cells were detached from the dish with $0.25 \%$ trypsin-EDTA $24 \mathrm{~h}$ following transfection. Cells were then washed and resuspended in $500 \mathrm{ml}$ PBS buffer. Transfection efficiency was determined by the percentage of green fluorescent-positive cells using a FACS system (Beckman Coulter, Miami, FL, USA).

Western blotting. Cells were collected and washed with PBS 3 times. Cell extraction solution $(100 \mu \mathrm{l})$ was then added and the mixture was sonicated at $240 \mathrm{~W}$ for $6 \mathrm{sec}$ and the cells were centrifuged at $13,000 \mathrm{x} \mathrm{g}$ for $10 \mathrm{~min}$. Cell pellets were placed in $4 \mathrm{X}$ denatured buffer and boiled for 3-5 min. Protein sample $(15 \mu \mathrm{l})$ was then added into each well of a $12 \%$ polyacryamide gel for electrophoresis and the blot was transferred onto a PVDF membrane at $90 \mathrm{~V}$ for $90 \mathrm{~min}$. Non-specific binding was blocked with $5 \%$ non-fat milk/PBS for $30 \mathrm{sec}$ and subsequently $4 \mu \mathrm{l}$ of the primary antibody in PBS was added and incubated for $90 \mathrm{~min}$ at RT. The mixture was washed with PBS 3 times and then incubated with $4 \mu \mathrm{l}$ secondary antibody in PBS for $90 \mathrm{~min}$ at room temperature. This mixture was then washed 3 times with PBS and the signal was developed with $50 \mu \mathrm{g} / \mathrm{ml} \mathrm{BCIP}+100 \mu \mathrm{g} / \mathrm{ml}$ NBT developing buffer and incubated for 5-10 $\mathrm{min}$.

Enzyme-linked immunosorbent assay (ELISA). Insulin and C-peptide were determined by ELISA kit (Diagnostic Systems Laboratories, Webster, TX, USA). Standards and equal culture 

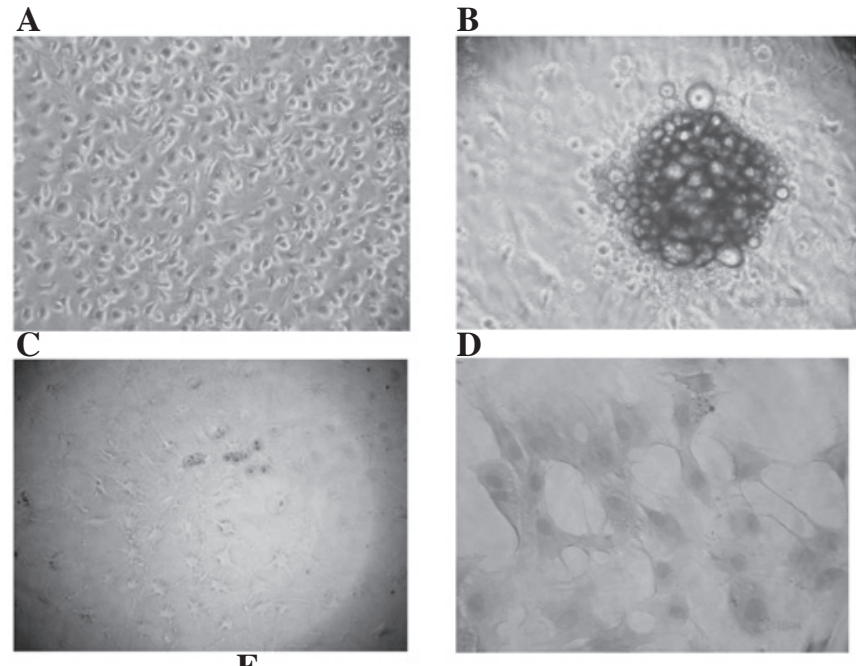

D

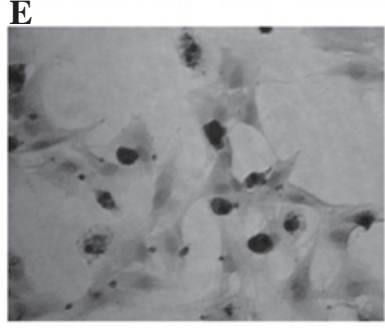

$\mathbf{F}$

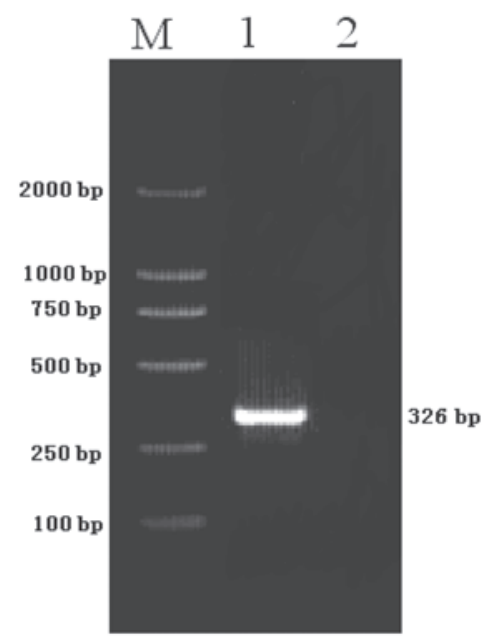

Figure 1. Primary culture of BMSCs and NSCs. Bone marrow cells were isolated from rat femurs and cultured in vitro. (A) Cell morphology of BMSCs after 6 days. (B) Neurosphere of NSCs after 3 days. (C) Extended dendrites were observed in the NSCs after 8-10 days. (D) BMSCs and (E) NSCs were analyzed by immunocytochemical staining using nestin antibody. (F) Nestin mRNA expression in BMSCs and NSCs was determined by RT-PCR analysis M, DNA ladder; lane 1, NSCs; lane 2, BMSCs. BMSCs, bone marrow stromal cells; NSCs, neural stem cells.

supernatant were added to the 96 -well plates. The absorbance was then measured with GENios spectrometer (Tecan Group Ltd., Männedorf, Switzerland) at $450 \mathrm{~nm}$. A relative optical density value was plotted using these standards and the concentration of insulin and C-peptide in the culture supernatant derived.

\section{Results}

Nestin mRNA is expressed in NSCs. Bone marrow cells from the femurs of SD rats were harvested and separated by Ficoll.
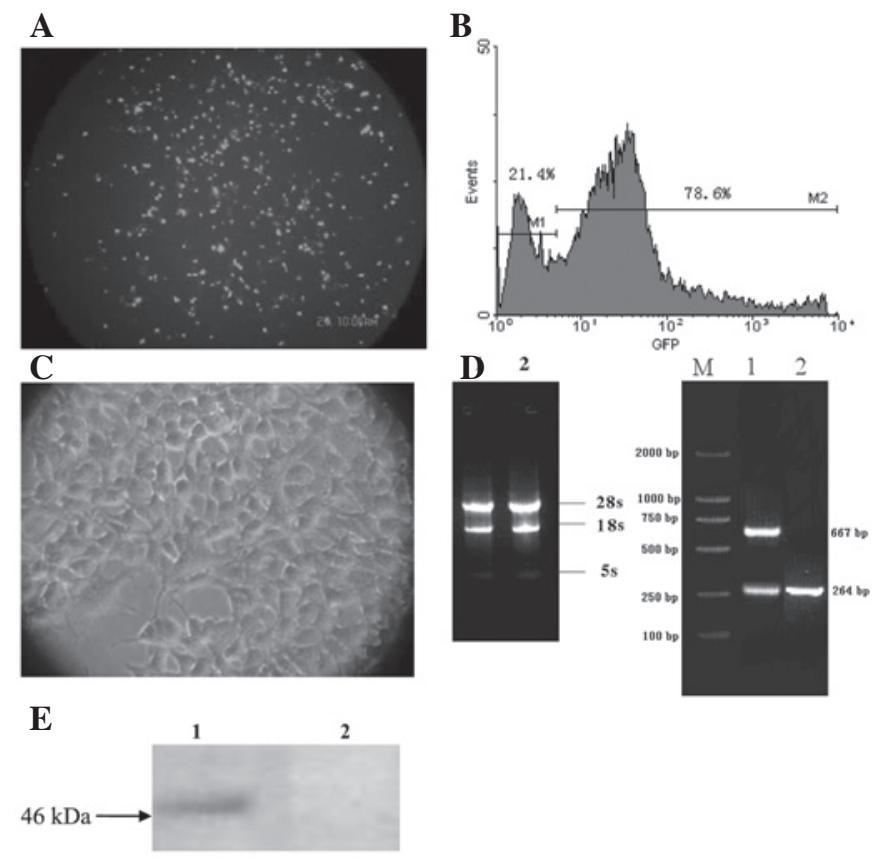

Figure 2. PDX-1 expression in NSCs. NSCs were transiently transfected with pEGFP-C2-PDX-1 plasmids (30 $\mu \mathrm{g})$ for $24 \mathrm{~h}$. (A) Fluorescent images of transfected cells were captured with a fluorescence microscope. (B) The transfection efficiency was quantified by flow cytometry. The M2 region indicates the percentage of GFP expression in total cells. (C) The cell morphology of pEGFP-C2-PDX-1-transfected NSCs was observed on the third day. (D, left) Total RNA was extracted 2 days following transfection and underwent electrophoresis. (D, right) The expression of PDX-1 mRNA on pEGFP-C2 and pEGFP-C2-PDX-1-transfected NSCs was analyzed by RT-PCR. Lane M, DNA ladder; lane 1, pEGFP-C2-PDX-1-transfected cells; lane 2, pEGFP-C2-transfected cells. (E) Protein expression of PDX-1 was analyzed by western blotting. Lane 1, pEGFP-C2-PDX-1-transfected cells; lane 2, pEGFP-C2-transfected cells. PDX-1, pancreatic duodenal homeobox-1; NSC, neural stem cell; GFP, green fluorescent protein.

Cells were cultured in L-DMEM with $10 \%$ FBS for the generation of BMSCs and cultured in neurostem cell medium for the generation of NSCs. BMSCs adhered to the culture dishes and grew rapidly following 6 days of culture (Fig. 1A). However, the NSCs formed neurospheres after 3 days (Fig. 1B) and dendrites of the NSCs appeared after 8-10 days (Fig. 1C). To characterize BMSCs and NSCs, immunocytochemical staining and RT-PCR of nestin were performed. Strong staining of nestin was observed in NSCs but not BMSCs (Fig. 1D and E). The RT-PCR analysis also confirmed that nestin mRNA was expressed in NSCs, but not in BMSCs (Fig. 1F).

Cells transfected with pBluescript-EGFP-C2-PDX-1 express $m R N A$ (667 bp) and protein (46 kDa). To induce cell differentiation, NSCs were transfected with pBluescript-EGFP-C2-PDX-1. Following 7 days of transfection, the green fluorescence of pBluescript-EGFP-C2-PDX-1-transfected cells was observed by fluorescence microscope (Fig. 2A) and the transfection efficiency was $78.6 \%$ by FACS analysis (Fig. 2B). The cells became round with larger nuclei and, 3 days after PDX-1 transfection, the nuclei-to-plasma ratio increased (Fig. 2C). The RNA of vector-only (pBluescript-EGFP-C2) or pBluescript-EGFP-C2-PDX-1-transfected cells was extracted and the expression of PDX-1 mRNA was examined by RT-PCR and PDX-1 protein was determined by 

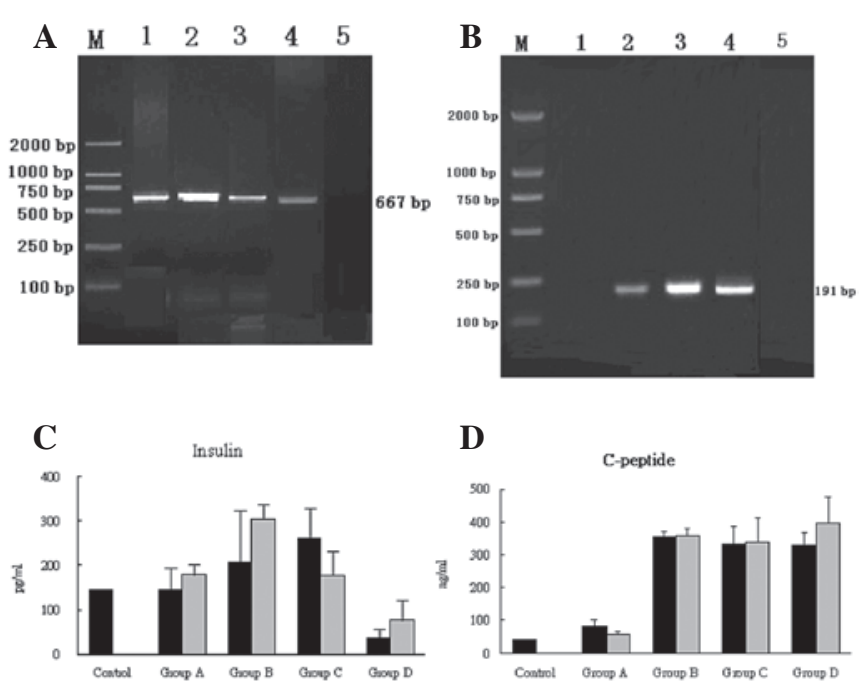

Figure 3. Effects of glucose and GLP-1 on PDX-1-transfected NSCs. (A) The PDX-1-transfected nestin-positive NSCs were treated with glucose and/or GLP-1. After $2 \mathrm{~h}$, the cells were harvested and the mRNA expression levels of (A) PDX-1 and (B) insulin in NSCs after various treatments were determined by RT-PCR. Lane M, DNA ladder; lanes 1-4, EGFP-C2-PDX-1-transfected NSCs with treatment with medium (lane 1), glucose (lane 2), GLP-1 (lane 3), GLP-1 and glucose (lane 4); lane 5, EGFP-C2-transfected NSCs + GLP-1 and glucose. Before (black bar) and after (grey bar) treatment of glucose GLP-1, or glucose + GLP-1, (C) production of insulin and (D) C-peptide was determined by ELISA. Control and groups A-C were EGFP-C2-PDX-1transfected NSCs with treatment of medium (control), glucose (group A), GLP-1 (group B) and GLP-1 + glucose (group C). Group D, EGFP-C2 transfected NSCs treated with GLP-1 and glucose. GLP-1, glucagon-like peptide-1; PDX-1, pancreatic duodenal homeobox-1; NSC, neural stem cell.

western blot analysis (Fig. 2D and E). Cells transfected with pBluescript-EGFP-C2-PDX-1 expressed mRNA (667 bp) and protein $(46 \mathrm{kDa})$. Neither PDX-1 mRNA nor protein expression was observed in vector-transfected cells.

Insulin mRNA was induced in the presence of glucose, GLPI and glucose + GLP1. To determine whether the PDX-1-transfected NSCs were responsive to glucose or glucagon-like peptide 1 (GLP1) challenges, insulin mRNA and insulin protein were measured using RT-PCR and ELISA. Following 7 days of culture, NSCs were transfected with vector or pBluescript-EGFP-C2-PDX-1. Cells were then cultured in $20 \% \mathrm{FBS} / \mathrm{L}-\mathrm{DMEM}$ only (control group) or with glucose (group A), GLP1 (group B) or glucose + GLP1 (group C). Vector (pBluescript-EGFP-C2)-transfected cells were cultured with glucose + GLP1 (group D) as a control. The PDX-1 mRNA was detected by RT-PCR in all EGFPC2-PDX-1-transfected cells (Fig. 3A). Subsequently, whether insulin was induced by glucose or GLP1 was examined. As shown in Fig. 3B, insulin mRNA was induced in the presence of glucose (lane 2), GLP1 (lane 3) and glucose + GLP1 (lane 4). Neither pEGFP-C2-PDX-1-transfected cells cultured with medium (lane 1) nor vector-transfected cultured with glucose + GLP1 (lane 5) produced insulin. To determine whether the PDX-1-transfected NSCs synthesized insulin protein, the supernatants were collected and determined by ELISA. Fig. 3C shows that insulin was detected in the control group $(145 \mathrm{pg} / \mathrm{ml})$, group A $(144 \pm 57.28 \mathrm{pg} / \mathrm{ml})$, group B $(208 \pm 117 \mathrm{pg} / \mathrm{ml})$, group C $(261.25 \pm 69.88 \mathrm{pg} / \mathrm{ml})$ and group D
$(271.25 \pm 89.68 \mathrm{pg} / \mathrm{ml})$ prior to glucose/GLP-1 stimulation. However, the insulin was not significantly released following a glucose/GLP-1 challenge. Similar results were observed in the production of C-peptide (Fig. 3D).

\section{Discussion}

Previous studies have shown that insulin-producing cells are generated from progenitor cells from various sources, including liver $(8)$, pancreas $(23,24)$, intestinal epithelium $(25)$ and embryonic stem cells (26). However, overcoming the rejection of transplanted $\beta$ cells remains a challenge. Moreover, it is difficult to obtain sufficient stem cells from these organs. Bone marrow is an abundant source of adult stem cells. This study examined the possibility of using bone marrow cells that differentiate into NSCs by transfecting the PDX-1 gene into BMSCs to generate insulin-producing cells. The production of insulin from PDX-1-transfected NSCs was confirmed by RT-PCR and ELISA. The current study suggests that bone marrow contains pluripotent cells that are capable of being reprogrammed to differentiate into insulin-producing cells

In pancreatic $\beta$ cells, GLP-1 regulates numerous genes that control insulin, glucokinase, glucose transporter-1 (GLUT-1), GLUT2 and hexokinase I (27-29). GLP-1 also enhances insulin secretion in a glucose-dependent manner. However, significantly increased insulin release was not observed in the presence or absence of glucose, GLP-1, or with glucose + GLP-1 in the PDX-1-transfected NSCs of the current study. The PDX-1-transfected NSCs spontaneously released insulin without glucose/GLP-1 challenge. These data suggest that PDX-1-transfected NSCs are $\beta$-like cells and further induction, including with nicotinamide and exendin 4 , is required to reach a higher degree of differentiation, as observed in native pancreatic $\beta$ cells $(13,30)$.

Campbell and Macfarlane reported that glucose, GLP-1 and insulin positively regulate the PDX-1 gene promotor in pancreatic $\beta$ cells (31). In the current study, glucose or GLP-1 induced the expression of mRNA and insulin in PDX-1-transfected nestin-positive cells, but no synergistic effect was identified. There are three possible reasons for this. Firstly, the expression level of plasmid DNA may have changed as the transfection system is different. In the current study, the plasmid was transfected by Nucleofector into the nucleus directly, not into the cytoplasm. Secondly, the concentration of glucose or GLP-1 was too high to induce a synergistic effect and thirdly, PDX-1 may be regulated through a pathway independent of glucose and GLP-1.

Multiple growth factors, including insulin, were added to the cell culture prior to transfection. However, neither PDX-1-transfected nestin-positive cells nor nestin-positive cells in the presence of glucose and GLP-1 produced insulin, suggesting that insulin production was induced by glucose and GLP-1 stimulation in PDX-1-transfected nestin-positive cells. Conversely, insulin production was not induced in nestin-positive cells in the presence of GLP-1 and glucose. That PDX-1 is necessary for glucose and GLP-1 to induce insulin expression was consistent with the results of previous studies $(32,33)$.

The length of time required for BM-derived nestin-positive cells to differentiate into insulin-producing cells was shorter in the present study compared with that in others $(13,34)$. There 
are two reasons for this difference. Firstly, the plasmid DNA was transfected into the nucleus directly and the expression reached a peak after $24 \mathrm{~h}$. Additionally, the amount of time for PDX-1 expression was shorter in the current study compared with that of others. Secondly, in the study by Gao et al, high concentrations of serum inhibited the differentiation of $\beta$ cells (35). However, in the current study, high concentrations of serum enhanced cell proliferation and cell-cell contact, resulting in a more rapid differentiation.

This study provides evidence that PDX-1-transfected BM-derived nestin-positive cells differentiated into insulin-producing cells following stimulation with glucose and GLP-1. However, more research is required to clarify the mechanisms of a single or synergistic effect of growth factors. Based on these findings, the source of insulin-producing cells appears to be unlimited for autologous transplantation for type-1 diabetes.

\section{Acknowledgements}

This study was supported by the Doctoral Initiating Project of Guangdong Province Foundation for Natural Sciences (project number, 8445583547-7001223).

\section{References}

1. Robertson RP, Davis C, Larsen J, Stratta R and Sutherland DE: Pancreas and islet transplantation for patients with diabetes. Diabetes Care 23: 112-116, 2000.

2. Shapiro AM, Lakey JR, Ryan EA, Korbutt GS, Toth E, Warnock GL, Kneteman NM and Rajotte RV: Islet transplantation in seven patients with type 1 diabetes mellitus using a glucocorticoid-free immunosuppressive regimen. N Engl J Med 343: 230-238, 2000.

3. Weir GC and Bonner-Weir S: Scientific and political impediments to successful islet transplantation. Diabetes 46: 1247-1256, 1997.

4. Weir GC and Bonner-Weir S: Islet transplantation as a treatment for diabetes. J Am Optom Assoc 69: 727-732, 1998.

5. Ryan EA, Paty BW, Senior PA, Bigam D, Alfadhli E, Kneteman NM, Lakey JR and Shapiro AM: Five-year follow-up after clinical islet Transplantation. Diabetes 54: 2060-2069, 2005.

6. Roche E, Reig JA, Campos A, Paredes B, Isaac JR, Lim S, Calne RY and Soria B: Insulin-secreting cells derived from stem cells: clinical perspectives, hypes and hopes. Transpl Immunol 15: 113-129, 2005.

7. Roche E, Santana A, Vicente-Salar N and Reig JA: From stem cells to insulin-producing cells: towards a bioartificial endocrine pancreas. Panminerva Med 47: 39-51, 2005.

8. Yang L, Li S, Hatch H, Ahrens K, Cornelius JG, Petersen BE and Peck AB: In vitro trans-differentiation of adult hepatic stem cells into pancreatic endocrine hormone-producing cells. Proc Natl Acad Sci USA 99: 8078-8083, 2002.

9. Herzog EL, Chai L and Krause DS: Plasticity of marrow-derived stem cells. Blood 102: 3483-3493, 2003.

10. Tuan RS, Boland G and Tuli R: Adult mesenchymal stem cells and cell-based tissue engineering. Arthritis Res Ther 5: 32-45, 2003.

11. Deans RJ and Moseley AB: Mesenchymal stem cells: biology and potential clinical uses. Exp Hematol 28: 875-884, 2000.

12. Pittenger MF, Mackay AM, Beck SC, Jaiswal RK, Douglas R, Mosca JD, Moorman MA, Simonetti DW, Craig S and Marshak DR: Multilineage potential of adult human mesenchymal stem cells. Science 284: 143-147, 1999.

13. Tang DQ, Cao LZ, Burkhardt BR, Xia CQ, Litherland SA, Atkinson MA and Yang LJ: In vivo and in vitro characterization of insulin-producing cells obtained from murine bone marrow. Diabetes 53: 1721-1732, 2004.

14. Lee K, Majumdar MK, Buyaner D, Hendricks JK, Pittenger MF and Mosca JD: Human mesenchymal stem cells maintain transgene expression during expansion and differentiation. Mol Ther 3: 857-866, 2001.
15. Chou YH, Khuon S, Herrmann H and Goldman RD: Nestin promotes the phosphorylation-dependent disassembly of vimentin intermediate filaments during mitosis. Mol Biol Cell 14: $1468-1478,2003$

16. Lendahl U, Zimmerman LB and McKay RD: CNS stem cells express a new class of intermediate filament protein. Cell 60: 585-595, 1990.

17. Taguchi M and Otsuki M: Co-localization of nestin and PDX-1 in small evaginations of the main pancreatic duct in adult rats. $\mathrm{J}$ Mol Histol 35: 785-789, 2004.

18. Yokoyama A, Sakamoto A, Kameda H, Imai Y and Tanaka J: NG2 proteoglycan-expressing microglia as multipotent neural progenitors in normal and pathologic brains. Glia 53: 754-768, 2006.

19. Yokoyama A, Yang L, Itoh S, Mori K and Tanaka J: Microglia, a potential source of neurons, astrocytes and oligodendrocytes. Glia 45: 96-104, 2004

20. Milanesi A, Lee JW, Xu Q, Perin L and Yu JS: Differentiation of nestin-positive cells derived from bone marrow into pancreatic endocrine and ductal cells in vitro. J Endocrinol 209: 193-201, 2011.

21. Ferber S, Halkin A, Cohen H, Ber I, Einav Y, Goldberg I, Barshack I, Seijffers R, Kopolovic J, Kaiser N and Karasik A: Pancreatic and duodenal homeobox gene 1 induces expression of insulin genes in liver and ameliorates streptozotocin-induced hyperglycemia. Nat Med 6: 568-572, 2000.

22. Sapir T, Shternhall K, Meivar-Levy I, Blumenfeld T, Cohen H, Skutelsky E, Eventov-Friedman S, Barshack I, Goldberg I, Pri-Chen S, et al: Cell-replacement therapy for diabetes: Generating functional insulin-producing tissue from adult human liver cells. Proc Natl Acad Sci USA 102: 7964-7969, 2005.

23. Bonner-Weir S, Taneja M, Weir GC, Tatarkiewicz K, Song KH, Sharma A and O'Neil JJ: In vitro cultivation of human islets from expanded ductal tissue. Proc Natl Acad Sci USA 97: 7999-8004, 2000.

24. Ramiya VK, Maraist M, Arfors KE, Schatz DA, Peck AB and Cornelius JG: Reversal of insulin-dependent diabetes using islets generated in vitro from pancreatic stem cells. Nat Med 6: 278-282, 2000

25. Suzuki A, Nakauchi $\mathrm{H}$ and Taniguchi H: Glucagon-like peptide 1 (1-37) converts intestinal epithelial cells into insulin-producing cells. Proc Natl Acad Sci USA 100: 5034-5039, 2003.

26. Assady S, Maor G, Amit M, Itskovitz-Eldor J, Skorecki KL and Tzukerman M: Insulin production by human embryonic stem cells. Diabetes 50: 1691-1697, 2001.

27. Wang Y, Egan JM, Raygada M, Nadiv O, Roth J and Montrose-Rafizadeh C: Glucagon-like peptide-1 affects gene transcription and messenger ribonucleic acid stability of components of the insulin secretory system in RIN 1046-38 cells. Endocrinology 136: 4910-4917, 1995.

28. Wang Y, Perfetti R, Greig NH, Holloway HW, DeOre KA, Montrose-Rafizadeh C, Elahi D and Egan JM: Glucagon-like peptide-1 can reverse the age-related decline in glucose tolerance in rats. J Clin Invest 99: 2883-2889, 1997.

29. MacDonald PE, El-kholy W, Riedel MJ, Salapatek AF, Light PE and Wheeler MB: The multiple actions of GLP-1 on the process of glucose-stimulated insulin secretion. Diabetes 51 (Suppl 3): S434-S442, 2002.

30. Ohgawara H, Kawamura M, Honda M, et al: Reversal of glucose insensitivity of pancreatic B-cells due to prolonged exposure to high glucose in culture: effect of nicotinamide on pancreatic B-cells. Tohoku J Exp Med 169: 159-166, 1993.

31. Campbell SC and Macfarlane WM: Regulation of the pdx1 gene promoter in pancreatic beta-cells. Biochem Biophys Res Commun 299: 277-284, 2002.

32. Cao LZ, Tang DQ, Horb ME, Li SW and Yang LJ: High glucose is necessary for complete maturation of Pdx1-VP16-expressing hepatic cells into functional insulin-producing cells. Diabetes 53: 3168-3178, 2004.

33. Hui H, Wright $\mathrm{C}$ and Perfetti R: Glucagon-like peptide 1 induces differentiation of islet duodenal homeobox-1-positive pancreatic ductal cells into insulin-secreting cells. Diabetes 50: 785-796, 2001.

34. Hori Y, Gu X, Xie X and Kim SK: Differentiation of insulinproducing cells from human neural progenitor cells. PLoS Med 2: e103, 2005.

35. Gao R, Ustinov J, Pulkkinen MA, Lundin K, Korsgren O and Otonkoski T: Characterization of endocrine progenitor cells and critical factors for their differentiation in human adult pancreatic cell culture. Diabetes 52: 2007-2015, 2003. 